\title{
The Structure of "Shuyo" = Cultivation: The Understanding of a Unique Japanese Educational Tradition within Translation*
}

\author{
Tadashi Nishihira ${ }^{\dagger}$ \\ Translated by Nadezhda Murray ${ }^{\ddagger}$
}

\begin{abstract}
Cultivation (shuyo) is not a translated term. However, neither has it been used consistently since the Edo period (1603-1867). Its "depth" is not visible simply from the "shuyo" theory of the Meiji period (1868-1912). This paper structuralizes the Edo and Meiji periods in synchronicity. In addition, it focuses on the translation of Western terms, in particular "cultivation," and examines the surrounding areas. The points addressed are 1) relations with politics, 2) relations with morals, 3) differences from care for health (yojo), 4) differences from spiritual exercise (shugyo), and 5) differences from skill and performance (keiko). The practices of "non"-modernity cannot be summed up within the categories of modern education. Hints thereto are found in "discrepancies" within translation. This is an attempt to examine a unique Japanese educational tradition as understood within translation.
\end{abstract}

Keywords: cultivation (修養); “non”-modernity ; translation ; spiritual exercise (修行); skill and performance (稽古); care for health （養生）

\section{Introduction: Defining the problem of "shuyo"}

Transmitting Japan's traditional climate of education internationally involves translation into foreign languages. However, for the education of "non"-modernity, this is no simple matter. As soon as the basic categories of modern education are employed for translation, somehow the perspective itself becomes a modern one. The phenomena of "non"-modernity are understood in "forms that fit into the modern framework," and accepted while dismissing

\footnotetext{
* This article was originally published, in Japanese, in Kyoikugaku Kenkyu (The Japanese Journal of Educational Research), Vol. 86, No.4, 2019. The author takes full responsibility for the wording of this paper.

† Kyoto University e-mail: nishihira.tadashi.7c@kyoto-u.ac.jp

e-mail: bekomoya@gmail.com
} 
the aspects that differ from modernity. This means the sharing and acceptance only of the "understandable aspects," leaving those which do not fit into the modern framework (those differently categorized or hard to handle) forgotten.

However, translation is not the issue. The true problem is the understanding of "non"-modern events in the language of modernity. Transmitting educational thought of the Edo period and earlier internationally has actually involved two stages: first understanding "non"-modern educational thought through the basic categories of modern education, and then transforming that into the languages of foreign countries. Naturally, discrepancies have arisen. However, these discrepancies also bring out the "non"- of non-modernity. Translation thus provides valuable hints toward the understanding of "non"-modernity (Saito et al., 2018).

"Shuyo" is one example of this. "Shuyo" represents one well-spring of education. However, its definition is not clear. It is not a translated term derived within the modern period; neither has it been continuously used since the Edo period. The history of "shuyo" in the Edo period is plentiful, but the thinkers of the period did not use the word (as a key concept). However, the word came to hold sway in the late Meiji period, and yet proved to be a flash in the pan which received no further attention later on. Observing the late Meiji period alone, as an independent entity, leads to a misunderstanding of the spread of "shuyo."

"Shuyo" has already been introduced overseas. Existing English translations include "self-improvement," "character-building," and "training." This paper focuses on the word "cultivation." "Keiko" has also been translated with the same English word, as has "shugyo" at times. In other contexts, "yojo" has been given the same English translation as well. This suggests that the concepts of shuyo, keiko, shugyo, and yojo form a consistent thread in the word "cultivation." Rereading from this perspective suggests that the word "shuyo" has indeed overlapped with yojo, keiko, and shugyo in use. This paper, therefore, addresses "cultivation" as a reverse import, calling it "shuyo."

To examine "shuyo," a comprehensive history of ideology is required. This paper, while no more than an introduction thereto, attempts to organize its arguments with a synchronous structure of the Edo and Meiji periods rather than a discussion limited to the late Meiji period, including the translations of Western terms. ${ }^{1}$

\section{Shuyo and politics: Does shuyo represent "the path to statesmanship"?}

Ironically enough, the strongest impression left by the word "shuyo" in the shuyo thought of the Edo period is the declaration of Ogyu Sorai (1667-1728) that "shuyo is unnecessary." Sorai separated "politics" from "shuyo," declaring that the latter was not needed for the former, that developing shuyo would not automatically enable good governance. Politics was, he said, an intentional strategy for governance. ${ }^{2}$

"Politics" and "shuyo" were so intimately connected that this constituted a major event in the ideological sphere. The cultivated (shu) person governs the nation under heaven. Shuyo was an essential condition for a good statesman. The premise, of course, was the sharing of Confucian thought. Cheng-Zhu Neo-Confucianism uses the phrase "shuko chijin" or "those who have cultivated themselves govern the people." The completion of individual personalities brings good social practice. Individuals must first cultivate themselves (kakubut- 
su/chichi, seii, seishin, shushin; study of the world, attaining knowledge, sincerity, integrity, and self-cultivation), and then govern society (seika, chikoku, heitenka; unifying the family, governing the state, peace on earth). The individual and society were continuous, with individual cultivation as the premise for social governance. ${ }^{3}$

What does it mean to possess virtue, then? To be a saint, as they appear physically in the scriptures. They followed a natural path under heaven. If anything, this natural path appeared within them. The path of the saint was, in itself, the natural path under heaven.

\section{- Sorai: "Shuyo is not necessary"}

Sorai summarily rejected these ideas. The "path of the saint" was not the natural path under heaven; it was an artificial creation. The saints were simply an artificial system ("reigaku keisei" or the elements of national order, conventions, leisure, judiciary, and politics) as the needed norms for governance (Watanabe 2010a, ch. 9).

Even so, the saints had not created an arbitrary system, but rather one based on common "human nature." Sorai called it "ever-present human feeling." The "path of the saint" was constructed based on this human feeling, and thus became the norm of governance common among humanity. Or perhaps each individual had their own inborn "character," to be "cultivated" (yo) and its characteristics made the most of in "study." The governing statesman used these in effective combination, a human resources theory based on respect for the individual (Watanabe 2010b, p. 205).

In this case, the common people do not need study to be governed. Sorai refers to the study of "the skill of governance." The governed people need only grasp the basic virtues. Study has nothing to do with the formation of virtue. Sorai essentially considered the common people to be fools.

How, then, are the people to be governed? This depends on "reigaku": conventions and leisure, as teaching in words is not effective. People are emotionally affected by conventions and leisure before they know it. This is not forcible oppression, but the configuration of customs and etiquette as "traditions" which become an accustomed part of daily life. From the people's perspective, there are mechanisms in unexpected places, bringing them unconsciously under the ruler's sway. Sorai's study is Machiavellian in nature: how cleverly can the people be ruled and the regime extended? Sorai argued for the "path" of the ruler, without reference to that of the ruled.

In this way, Sorai discarded shuyo. The world does not govern itself through the governor's self-cultivation; if anything, systems are required because virtue will not bring about governance. "Saints" are not great people but special governors. Sorai made politics independent of shuyo, as a skill for governance. ${ }^{4}$

\section{- Dore: Education in Tokugawa Japan}

The British sociologist R.P. Dore depicted this situation from the perspective of education. His first reference to "shuyo" is in regard to Sorai, who "rejected the whole assumption that the purpose of studying the classics was the moral cultivation of the individual" (Dore p. 23).

In this formidable work on the education of the Edo period, the word "shuyo" first appears in the phrase "shuyo is not necessary." This suggests just how little focus there was on "shuyo" in educational studies. While generally corresponding to "cultivation," "shuyo" ap- 
pears only a few times and is not listed in the index. The next time this word appears in Dore's book is when criticized through "practical education," saying that what is important is actually useful knowledge, not "shuyo." "Shuyo" was understood in the sense of the "moral use value of Confucianism," as seen by the political administrator.

However, Dore was not uninterested in "shuyo." Rather, he uses various terms to refer to the area at issue, such as "a system of ethical training through study of the Confucian classics" (ibid p.34) and "mental training in the virtues" (ibid p.49). Shuyo in the Edo period was not referred to with the term "shuyo." Individual thinkers used their own words, while the word itself had a different topology. Its spread is referred to here as "shuyo/cultivation."

In this way, shuyo in the Edo period was connected with politics, while "keiko" was not. The concept of "keiko" did not change even when under the protection of the regime of the time. Similarly, "shugyo" and "yojo" were rarely directly influenced by politics. In contrast, shuyo (in particular within the Neo-Confucian tradition) was deeply connected to politics and governance. Shuyo was the path to governance. It was not, therefore, the path to being governed. It was not until the Confucian scholars of Japan revised their view of Confucianism that shuyo came to be understood as a requirement for the "governed" as well.

\section{Shuyo and morals: Is shuyo "disciplinary training"?}

Shuyo overlaps with "dotoku" (morals). However, it is not social ethics. Rather than exterior norms, it is individual ethical practice. It is the ingenuity (desire/expectation/effort) of the individual who wants to be enhanced. It is not a matter of polishing the character through "skills and art," like keiko. Nor is it a removal from daily life, like shugyo. Anyone can practice shuyo to polish their character in the midst of daily life. It is the morals of the people.

This point has been noted as a characteristic of Japanese Confucianism (Tokugawa Confucians). However, precisely speaking, Neo-Confucianism had an eye to "the people (the governed)" as well. Anyone could become the "governor." The path to statesmanship (princehood) was open to everyone. In contrast, the Tokugawa Confucians abandoned this possibility. Rather than bet on the possibility that the people would take up "governance," they argued that the people were to remain what they were and cultivate themselves in daily life, living in harmony with existing society. Representatives of this view include Nakae Toju (1608-1648), Ito Jinsai (1627-1705), and Ishida Baigan (1685-1744) ${ }^{5}$.

\section{- Toju's "gakumon" and Jinsai's "shui"}

Nakae Toju emphasized the "interior": reflecting on oneself to put one's interior life in order. Toju used the word "gakumon" (studying and questioning) rather than "shuyo." Naturally, this was used in a different sense from its modern Japanese sense of academic study. "Gakumon means purifying the taint of the heart and improving behavior," he wrote in Okina Mondo. Toju's gakumon was close to a behavioral practice, and different once again from standard Confucian learning. Toju, for whom filial piety was important, recited the Scripture of Filiality every morning, much as the sutras are read in Buddhist ceremonies. He learned to read Confucian scriptures by following along with people whose custom was to read the sutras (Koyasu 1998, Ch. 1). Toju's gakumon constituted the daily practice of shugyo for 
oneself, rather than the indoctrination of the people.

Uchimura Kanzo (1861-1930), who introduced Toju as a "representative Japanese," emphasized that his only desire was to be "correct." In a book meant for Western society, Uchimura presented Toju's ideology as overlapping with that of Christianity (Uchimura 1908, below).

However, shuyo is not necessarily directed at the interior; personal relations are important too. Morals are cultivated in daily interaction (ethical personal relations). Ito Jinsai, a merchant from Horikawa in Kyoto, argued (as the final stage of his ideological meanderings in youth) that the daily duties of ordinary people were an opportunity for shuyo as they were. Jinsai called this "nichiyo" or daily use, just as in the term for everyday goods; ordinary profane duties could be shuyo in themselves (Yamamoto 2010).

Overcoming oneself is not the point. Making the mind an independent teacher is wrong. Morals are bestowed from the start (good from the starting point). However, they are weak and must be nourished and cultivated (expanded). Jinsai called the ethical foundation of these teachings "shui" or "acts of cultivation."

"Shui" is distinguished from "hontai": Jinsai focuses on shui (the practice of cultivation) rather than hontai (principles and ideals). The path of hontai exists beyond humanity, but the path of shui is realized only through human practice. Without people, there is no path. Hontai alone is void. Jinsai, disliking this void, focused on the "actual things" living and operating in actual human relations (Doshimon, Vol. 1 Ch. 14).

For example, in terms of hontai, good and evil are utterly different, while in terms of shui, the path can be found by even the slightest increase in good and decrease in evil (meliorism). Elsewhere, in hontai, "jin" or humaneness is an ideal, but in shui it prompts small acts of compassion, or "do." Trying to consider others and be true to oneself in everyday life will eventually result in jin.

In this way, both Toju and Jinsai argued for shuyo for the people, not for the governors. The governed perform shuyo, doing their best within the scope they can in everyday interactions. That is the path. The profanity of the everyday itself becomes the path. Therefore, concepts beyond the profane are weak, leading to weak perspectives on reforming society.

\section{- Discipline and souci de soi (care for the self)}

One recalls Michel Foucault's "discipline": the process of spontaneous obedience, or of becoming a subject in obedience to morals. Can we call the ideologies of Toju and Jinsai ultimately "discipline" as well? Discipline does not take away subjectivity; if anything, it encourages it. However, this "subjectivity" is double: Foucault uses the double meaning of "subject" (central figure or one ruled by a monarch) to state that "subjection" may have both meanings. The individual must undergo one to achieve the other. The individual must be trained to suit the society. ${ }^{6}$

Both Toju and Jinsai discussed the "subject" of the common people living in existing society. Was their "shuyo" discipline? We noted above that Uchimura Kanzo understood Toju through the lens of Christianity. Conversely, Inoue Tetsujiro (1855-1944) emphasized the differences between the two. In contrast to Toju's focus on loyalty and filial piety, he argued, Christianity's focus was on the relationship with God, taking relationships of loyalty to sovereigns or parents lightly (Inoue 1900).

In Inoue's understanding, Toju's “interior" was obedience to "sovereigns and parents," 
turning to loyalty and filial piety within the existing system. In contrast, according to Uchimura, Toju's "interior" turned toward the "transcender," toward ideals beyond earthly authority. In other words, Toju's "conscience" (innate goodness) was not limited to obedience to the orders of earthly authority. Inoue considered this dangerous, and tried to wrap up Toju's shuyo in the safe logic of "docile obedience through discipline." Inoue understood Toju as "discipline," while Uchimura found in him a logic not accountable for by discipline.

In his last years, Foucault searched for this logic not accountable for by discipline, and tried to find "self-governance" distinct from political domination in classical ideology. He called this "souci de soi" or care for the self. It amounts to "governing domination over the self," but not necessarily political domination (relationships of power).

"Care for the self" is the practice of changing oneself. The subject is transformed in order to escape the status quo. Foucault calls this "the price to be paid for access to the truth," or "purification, training, disposal, shifting gaze, changing existence" (Foucault 2004 p. 19). We may add Toju's "gakumon" to this list, or else Jinsai's "shui." The shuyo ideology of the Edo period (perhaps because of its uniquely liminal nature as the "pre-modern period," caught between ancient and modern) is an interesting field within which discipline and care for the self are at odds. Foucault, in his last years at least, would surely have focused more on the messy shuyo ideology of the Edo period than the shuyo theory of Meiji. ${ }^{7}$

\section{Shuyo and shugyo: branching off at the point of usefulness}

Shuyo is sometimes used synonymously with shugyo, while the differences between the two are sometimes pointed out from the perspective of the latter. However, the definition of "shugyo" is not perfectly clear either. There is no direct translation in Western languages. Some have argued for "asceticism" as the closest equivalent (not bad, given that the Greek askesis means "physical effort/training/practice"), but "asceticism" tends to be understood as a denial of desire, overemphasizing only a single aspect of "shugyo."

The focus today in this context is on the "exercices spirituels" (also translated as spiritual cultivation or training/exercises) of the French scholar of ancient philosophy Pierre Hadot, who described them as "individual practices intended to transform the self through self-will" (Hadot 2002a, p. 179). This is, in the terms of this paper, shuyo (cultivation). According to Hadot, the philosophy of ancient Greece was invariably accompanied by this practice. It was, thus, all shuyo as well.

The problem is in the word "spirituels" or spiritual exercises in English; Hadot feels that this word's meaning is not restricted. If anything, if refers to the entire personality. They are exercises for the whole person. However, this is different again from "shugyo." It is not religion. Hadot emphasizes that these exercises were not found within a search for religion or spirituality. Rather, he arrived at them while exploring the methodology involved in reading ancient texts. The philosophy of ancient Greece must be read as "exercises for the whole person." He uses the phrase "philosophy as a way of life (une manière de vivre)." Philosophy changes actual daily life (Hadot 2002b, p.290).

This is not "philosophy as mere theory," nor is it "religious shugyo." This paper reads these "exercises" as "shuyo." Through these exercises, we try to reshape the concept of shuyo from the interior. 


\section{- Yuasa Yasuo: "Shugyo"}

Yuasa Yasuo (1925-2005) wrote on shugyo in Japan, which he translated as "cultivation" (Yuasa, 1987). What is "shugyo = cultivation," then? Yuasa defines shugyo as the work of "moving beyond health," in contrast to "chiryo" or healing, which is "moving from sickness to health." Shugyo is the movement from "average to above average": "the practical attempt to enforce on one's own heart and body restrictions stricter than those of the societal norms to which the average person is in thrall" (Yuasa 1977, p.285).

According to Yuasa, Eastern shugyo theory does not divide the various capacities. It grasps the entire heart and body holistically, with the "character" in the middle. If anything, skills and crafts are meaningless, because they do not improve the character. Japanese shugyo sought the perfection of the character (personality) in the everyday dimension. ${ }^{8}$

This meaning is close to that of shuyo, but Yuasa does not use the latter word; as well, seen from this paper's discussion of "shuyo = cultivation," Yuasa's usage of shugyo is stricter. He understands it as the previously mentioned "practical attempt to enforce on one's own heart and body restrictions stricter than those of the societal norms to which the average person is in thrall."

In the background of this "strictness" is the awareness of "evil" and "sin," as the essential nature of humanity. To move away from these, one imposes "strict restrictions" on oneself. In contrast, shuyo (in typical Neo-Confucianism) considers human nature essentially "good." Therefore, going back to the origin is sufficient: not strict restrictions, but obedience to nature in returning to the source ("fukusho" in Neo-Confucianism).

This paper grasps the difference between shugyo and shuyo in the context of these differing views of human nature. Shugyo is strict, based on the view of human nature as evil/ sinful, while shuyo is gentle, based on the view of human nature as good.

Naturally nothing is so simple; shugyo stands in opposition to the problem of "external power" in other aspects. It is not real when conducted only with "internal power," but is understood as necessarily developing into "external power."

\section{- Shuyo in Kiyozawa Manshi: Self-cultivation and faith in external power}

The Meiji-period Buddhist philosopher Kiyozawa Manshi (1863-1903) addressed this question, taking the problem of shuyo very seriously and personally: "All human suffering is shuyo." However, his grasp of shuyo was extremely similar to shugyo.

Kiyozawa's origin point is the "inefficacy of the self." The struggles of life cannot be overcome through individual effort. There is nothing for it but to believe in and cling to Nyorai (the Buddha), to leave everything to the "Great Compassion." And yet, we cannot bring ourselves to do this. Here, shuyo becomes necessary. We conduct shuyo in order to confirm the origin point at which "the only thing to do is leave it up to the Buddha." Kiyozawa compares life to a sumo wrestling ring, in which we face life's struggles with the fierceness of a wrestler, chiding ourselves each time we are broken; in his diary, he wrote that "it is due to a lack of samatha-vipasyana calmness. We must work hard for shuyo."

However, there are some deviations in Kiyozawa's shuyo. Does it always move toward faith in external force? Kiyozawa focused on "self-reflection (internal reflection, internal observation)." Reflection on the "spirit" at the heart of the self would grant knowledge of the Heavenly Path, which in turn would lead inevitably to faith in external force. However, in another location, he distinguishes "shuyo through internal force" with "faith in external 
force." While the struggles of life may become a source for shuyo through internal force, they do not necessarily serve thus for faith in external force. In that case, one is abandoned to the "wandering heart of internal force," where Kiyozawa looks for a change of direction. Working toward shuyo through internal force enables one to know one's own limits, and thus to turn toward faith in external force. Knowing the limits of self, one changes direction; shuyo takes place to this end.

The connections made by Kiyozawa between shuyo and faith (faith in external force) are not clear. However, in this paper's usage, his use of shuyo is essentially shugyo. He calls for a shift from "internal force" in shugyo to "external force," referring to the process as a whole as shuyo.

\section{- Usefulness in secular society}

Another issue distinguishing shugyo and shuyo is "usefulness." Shuyo is expected to be "useful" in secular society, in contrast to which shugyo goes beyond being "useful."

Nitobe Inazo (below) distinguished the "horizontal" and the "vertical" in his Shuyo. While the horizontal axis is the personal relations (politics/economy) of secular society, the vertical axis points to God (in the directions of heaven/of the universe). The vertical axis has the potential (the risk) to go beyond the usefulness of everyday life (Nitobe 1979-7). ${ }^{10}$

Shuyo is a yearning for growth on the horizontal axis. The self changes, which changes the family, which improves life. The wisdom fulfilling the ordinary people's expectations to this end is shuyo. Through its practice, the character is ameliorated. Thus, as a result, good outcomes ensue. It is not recommended to pursue shuyo to the point of discarding "good outcomes."

However, shugyo moves on the vertical axis, at times to the extent of discarding "good outcomes." Even if it means turning one's back on the expectations of others and cutting family ties, shugyo takes priority. Not only going beyond usefulness in secular society, it is the pursuit of the vertical axis to the point of individual health damage (on this point, shugyo is the polar opposite of "yojo," and this is where asceticism is understood as the denial of desires).

Naturally, this is an extreme case, and in most situations the borderline between shuyo and shugyo is fuzzy. However, this paper distinguishes them based on their views of humanity and on the point of usefulness in secular society. Precisely speaking, having thus distinguished shuyo and shugyo, the whole can be understood as shuyo = cultivation.

\section{Shuyo and yojo: "Originally, shuyo is yojo"}

Does shuyo promote good health? Can shuyo be in favor of comfort and joy? Amid diverse debates, the focus here is on Kaibara Ekken (1630-1714).

\section{- "Caring for the spirit": Kaibara Ekken}

According to Ekken, "yojo" means "caring for the spirit (ki)," or improving the circulation of ki energy. Internal ki must not be dammed up; "true ki" must be collected in the body's energy centers through good posture and quiet breathing. No anger, no fear, few words, few desires. Maintaining the same posture for too long is undesirable. 
Kaibara's Yojokun thus comes off as a practical manual at a glance; Tsujimoto Masashi was the one to reconsider it as a discussion of shuyo. Ekken's "yojo," he says, is not simply management of physical health, but also a theory of shuyo. In the background of this idea is the criticism of the slighting of the body, and further a radical criticism of the pre-modern Confucian understanding (as previously seen in Sorai) which slights the "ideology of ki" (Tsujimoto 2011, Ch. 1-4).

Ekken saw "caring for the spirit" and "learning the way" as a unity. Interestingly, with regard to "caring for the spirit," he distinguishes "laymen," "cultivators of immortality," and "profane Confucians." "Laymen" simply follow their desires, without caring for their spirits. "Cultivators of immortality" care for their spirits, but are not fond of "the way." "Profane Confucians" spend their time arguing about the way, without caring for their spirits, and thus "do not know the way of shuyo and cannot preserve their natural span" (Yojokun Vol. 1). The last-named type (louru in Chinese) refers to the Kimon school (disciples of Yamazaki Ansai), who looked down on the practice of yojo, mocking it as worth not even one hundredth part of "discussing the heart," according to Ekken's late work Jigoshu.

Ekken is basically an inheritor of Neo-Confucianism and its "reason" (somewhat dubious in the case of his late work Taigiroku). He admits to the existence of a universal "reason" and clarifies individually objective "reasons" (kakubutsu kyuri, or finding the reasons behind natural laws). Ekken turned toward the individual "reasons" of objects and ideas. He followed practical studies such as herbalism and natural history, pursuing the natural sciences such as astronomy and geology. His theory of yojo is a part thereof: the practical "technique of handling," based in the "reason" of the human mind and body. However, this is at the same time the path to be put into practice ("courtesy"). Academic study served as "skills for learning and following the path," not simply a manual.

\section{- The conflict between yojo and duty}

Ekken's theory of life is summarized at the beginning of his Yojokun. Taking good care of the bodies given to us is the basis of "filial piety" to the heavens and our parents; there is no way to serve them with a damaged body. It is wrong to injure any part of the body, even the skin or hair, without reason. This is the ideology of "the body entire."

However, as an early modern samurai (of the Fukuoka domain), Ekken was also prepared to give his life for his duty. He faced the conflict between "yojo," fulfilling his natural span without injuring the "body entire" given to him by his parents, and the readiness to give his life whenever his duty called for it. Ekken chose to prioritize duty. Life was the holiest thing he knew, but must sometimes be given up for rulers, parents, friends, teachers, in short duty. Life was holier than riches, and duty holier than life (Shogakukun, Vol. 2).

This problem presented a struggle for many early modern Confucians. Yamaga Soko (1622-1685) questioned whether a samurai who became ill should "heal (practice yojo) well, recover, and return to his work," or whether he should "endure, work through it, and consider it well done if he dies of it," saying that there were points on both sides and that it depended on the person and the illness. He also wondered whether it was holier to "die gloriously in battle" or to "live long and become famous," deciding that while the future was an unknown, in the present it was ideal to make one's name in death. "Die when the time to die comes, and do not die otherwise": this "categorizing of duty" was important to him.

Manase Dosan (1507-1594), the father of the revival of Japanese medicine, argued for 
"dying well." To practice yojo (heal) and remain free of illness was done to that end. This could mean living out one's natural span, or dying gloriously for duty. In Ekken's terms, the former was "normal" and the latter "unusual." Failing to take care of the body in normal times could mean being unable to fight when it matered, failing thus to protect life. It was essential to care for the spirit in normal times and "face unusual events bravely." This ideology of "yojo in normal times for the sake of dying well" was notably once again emphasized in prewar Japan's imperial nation-state (Imamura 1967, p. 661).

\section{- Health and hygiene}

However, from the late Edo period (Kasei era) on, this debate falls out of view. Samurai were no longer the only readers, and the debate was less personally meaningful. Different yojo, then, became an issue depending on class. Come the $19^{\text {th }}$ century, however, Western hygienics made ethnic differences an urgent issue. The yojo of "countrymen" became needed (in order not to lose out to Westerners) (Takizawa 2003).

From the perspective of modern medicine, yojo first developed into the modern "health methods" upon cutting its ties with shuyo. Takano Choei (1804-1850) translated Dutch hygienics as the "Dutch record of yojo," but Sugita Gentan (1818-1889) used "health science," the latter originating in the German Gesundheitlehre and reliant on the physiological science of Western Europe. It did not include shuyo. Yojo first became "hygienics" on a level with modern medicine when it was disentangled from shuyo.

In the Meiji period, "health" was a focus in school education as well. A "well-regulated body" was required for the establishment of the modern nation-state and the development of capitalism. Modern schools separated children from the world of their daily lives and corrected their postures and ambulation, introducing military exercises as well. By remaking the body, they were trying to remake the spirit.

Here, in fact, "kenko" (health) and shuyo come together once again, on a different plane from yojo, having once become independent therefrom. The plane on which they met was that of the purpose of "being useful to the nation." By the late Meiji period, when the theory of shuyo made its presence felt widely once again, "yojo" was gone for good. Meiji-era shuyo addressed mainly "being useful to the nation" (discussed below) rather than "caring for the spirit." In parallel, yojo had become Western medicine and hygienics. Shuyo and hygienics were both to fulfill important functions in ensuring useful human resources for the nation in the imperialist nation-state.

Saigusa Hiroto (1892-1963), who wrote on the history of technical thought, says that "shuyo originates with yojo." 12 Naturally, the yojo of the body was not historically the core of shuyo. If anything, "daily practical morals prioritized the spirit, even at the cost of punishing the body." Working to improve the spirit with little concern for the body was "a regular practice of people forced to conduct shuyo by their superiors." However, "character training via the spirit" alone does not lead to shuyo. Here, Ekken's Yojokun argues that "one must reward one's own body." Precisely, he spoke for the wisdom of the ordinary people to this effect. Therefore, "there was some sense of resistance in almost all the moralists recommending physical yojo to people with regard to the profane authorities and the hypocrites who fawned on them" (Saigusa 1956, p.5). The perspective of shuyo did not favor its fawning application to the secular world. 


\section{Shuyo and keiko: Cultivation, culture, Bildung}

There are many English translations for "keiko," including practice, training, lessons, and cultivation. The last is "culture" in French (self-cultivation is "culture de soi"). The French "culture" is also the translation for the German "Bildung" (along with "formation," "éducation" and so on). While the categorization differs by language, they all overlap somewhat, allowing for some misalignment. Do we translate "Bildung" as keiko or shuyo, then?

\section{- Self-cultivation}

Some studies have approached Japanese martial and fine arts as self-cultivation (Carter 2008). First, they consider the "do" or way, as in sado (tea ceremony), judo, and so on. This "way" is not a sport, a hobby, or a career, but a "way of life." When taken seriously, these arts are in themselves "satori" or enlightenment. However, to attain this, life-long self-cultivation is required. Next they focus on "meiso" or meditation. "Concentrate on your breathing, meditate, control your emotions, and move forward to satori." Here "self-transformation" is called self-cultivation.

Meiji-era shuyo theory also focused on breathing, beginning with the "way of meditation" of Okada Torajiro (1872-1920). Ashida Enosuke (1873-1951), who took up Okada's teachings, emphasized the "inner gaze." This is not formalized shugyo. Teachers' Shuyo in Composition Education cites the teacher's podium and the exercise field as practice spaces for shuyo. "Find the practice space for shuyo nearby and practice an orderly life in all positions." "Regard your interior" and "continue your practice" in your daily work. Ashida referred to this as shuyo (Ashida 1988, Ch. 2).

Another study on $19^{\text {th }}$ century Japan considers interdisciplinarily the social phenomenon of the mixture of Confucianism, Buddhism, and Shinto in popular religion at the time (Sawada 2004) $)^{13}$. The key concept is personal cultivation. This was "the moral, ritual, physiological, and/or educational processes, by which individuals were believed to attain well-being" (Sawada p.3). She goes on "This area can only be expressed in English as religion, morality, divination, health, and education, but the wording in Japan at the time referred to a unified effort" (ibid). Health promotion guidance connects with divination and with specific ceremonies. Not restricted to individual traditional religions (Confucianism, Buddhism, Shinto), it crosses the borders between popular and high culture as well. Diverse forms share a baseline directionality, which she calls personal cultivation or personal improvement, or the desire to enhance oneself.

Through these perspectives from overseas, we confirm new "ways of categorization," words "summing up" diverse expectations and techniques rooted in the lifestyles of ordinary people. The use of the word cultivation is what enables discussion of the common "directionalities" at the base of these diverse attempts.

This paper addresses this "cultivation" as "shuyo," grasping it as the area forming "the basis of practice."

\section{- Nitobe Inazo: Bushido and Shuyo}

How did the thinkers of the Meiji era approach the area labeled overall as "cultivation" by English-language scholars? Let us consider Nitobe Inazo (1862-1933). When principal of the First High School, he discussed the topic of shuyo extensively, defining it as "cultivating 
the body and caring for the heart." "Through this will, the self dominates its body." While based on "overcoming the self," his stance also emphasizes the "yo" or "caring" part of "shuyo," arguing for the kindness of painstaking upbringing and education (Nitobe 1911).

However, the point is the "subjective character." Asians [he wrote] have weak "characters as individual selves," with undeveloped "assurance of self" and weak "sense of responsibility. Here, the purpose of shuyo is the formation of the "character as individual self." It requires no special techniques; daily life is in itself shuyo. "With everyday shuyo," true value will reveal itself in unusual times. This was what the young people of the time wanted to hear, and the book was popular among young men and married women in rural villages.

Nitobe himself was aware that the book's contents were commonplace. From today's perspective, indeed, Nitobe's "shuyo" ideology functioned to pin poorly educated young people down to their status quo. If not that, then it enveloped rural young people and married women in shuyo and functioned to turn them toward their national duties (after Foucault, to render them subjects by subjectifying them).

However, here let us focus on the relation of Nitobe's understanding of shuyo with his English book on Bushido. According to the latter, the samurai were the "beau ideal" of people in Japanese society, supplying all classes with a moral standard (Nitobe 1899, Ch. 15). Was bushido a form of shuyo? Strangely enough, Nitobe never touches on the relationship between the two.

When writing Bushido at age 37, Nitobe had no special investment in the word "shuyo." Naturally, the romanized "shuyo" never appears in the English text. Instead, a wide variety of verbs are used in reference to shuyo. In chapter 10, discussing "the education and training of a samurai," he refers to "build[ing] up character" and to "the exercise of self-control." However, there is no sign whatever that he considered the word "shuyo" important.

Elsewhere, when he began to discuss the word "shuyo" in Japanese, aged 48 to 50, he never presented it in English. Shuyo was for the common people of Japan. Nitobe himself may have been telling the same story in different words for different audiences, but the message fulfills different functions for different readers. The purpose of Bushido was the introduction of Japanese culture, not the direct provision of "hints for living" to Western readers. In contrast, Shuyo encouraged the practice of shuyo, providing "hints for living" to the ordinary people as a manual for life.

This difference has something in common with "elite culture" versus "popular culture." Within Nitobe, "liberal educationism (First High School students)" and "shuyo-ism (girls from mountain villages)" shared the commonality of "improving character through effort." However, they were not equal recipients of culture. A focus on the point of "...through the acquisition of culture" led to liberal educationism, while an emphasis on "working hard at one's own job, regardless of the acquisition of culture" to popular culture-style shuyo-ism (Tsutsui 1995, p.138).

In fact, for an emphasis on the "acquisition of culture," keiko would have been more suitable than shuyo. However, at that time (as Karaki Junzo complained), the physical body was taken lightly, and the word "keiko" had no place in university academism. "Culture" referred to the "knowledge" acquired through the written word (Karaki 1963), not to the acquisition of special skills or arts. Character was improved through acquiring new Western knowledge.

Further, when the issue of "character improvement" receded and the "acquisition of 
Western knowledge" came to the fore, liberal educationist "kyoyo (liberal arts)" came about. From the perspective of "shuyo = cultivation" in this paper, liberal educationist kyoyo meant book-smarts, with no connection to keiko, shugyo, or yojo.

\section{- Shuyo, kyoyo, Bildung}

There was no consistency to the concept of shuyo in the Meiji era. It did not appear in the early-Meiji enlightenment ideology. The journal Meiroku Zasshi did not address the topic of shuyo. Its oldest Meiji-era appearance is thought to be in the translation of Smiles' SelfHelp (Wang 2004). The free translation means that the source term cannot be confirmed, but this work of translation served to separate the term from Confucian traditions and to use it to express the principles of a new era. Christian leaders also chimed in (Tokutomi Soho, Yokoi Tokio, Matsumura Kaiseki, Uemura Masahisa, Uchimura Kanzo). However, their shuyo was sometimes used as a prelude to "faith," and sometimes criticized for not attaining faith (Section 3 herein). The term was all too vulnerable to assorted usages.

The German "Bildung" was not translated as "shuyo," perhaps in order to avoid the hints of Confucianism clinging to the latter word. However, in his consideration of the Bildung concept, Masu Nobuo writes that "while Hegel's Bildung may be translated as shuyo, it cannot easily be translated as kyoyo" (Masu 2016). If Bildung had been translated as shuyo and thus received into Japanese, its ideology might have entered Japanese as something other than an abstract "formation/cultivation/kyoyo," while Confucian thought might not have been confined within the narrow understanding of service to the imperial state, functioning as a living ideological font of greater potential.

\section{Conclusion}

The heart of shuyo is "jiko-shuyo" or self-cultivation: cultivating the body, caring for the heart, and enhancing the self. It is not an approach to others, nor is it compelled by others. "Shuyo" is an intransitive verb. Much of it has overlapped with moral improvement. In that context, it has also been described as "practicing moral and spiritual self-cultivation" (Tucker 1989).

This may be close to shugyo in some situations and to yojo in others. Sometimes mastery of the self apart from worldly desires is emphasized, while at other times social success is expected. What is important is that "shuyo" has not always been recounted using the word "shuyo" itself. This paper has specified the area covered by "shuyo" through reverse-importing the word "cultivation." The issue area of "shuyo = cultivation" is larger than that of the word "shuyo."

The relations of shuyo and politics were diverse; it is important to note, however, that when compared with yojo, shugyo, and keiko, shuyo has always involved a strong awareness of political relations. It has also been related to morals. In that instance, it is possible to grasp shuyo as "discipline." However, it is worth focusing on the possibility resonating with the new phase Foucault calls "care for the self." As well, overlapping with yojo, shuyo demands health through caring for the spirit. In contrast, health was not the objective of shugyo. In comparison with shugyo, shuyo addressed usefulness in secular society, while shugyo's tendency (potential/risk) was to go beyond that issue. Further, in comparison with 
keiko, the latter requires "acquisition of skill," while shuyo did not work through skills. Shuyo contained the longing of the ordinary people, with no opportunities to encounter special "skills (culture)."

Sharing "non"-modern culture internationally is not simply a matter of transmitting it overseas. Only in dialogue with overseas perspectives do "Japanese traditions" become fully visible. Japan's unique educational traditions, as understood in the process of translation, deserve great care.

\section{Notes}

1 Due to limited space, quotations from original texts have been omitted and references to existing research abbreviated. The task of this paper is limited to defining "shuyo" as the area under discussion.

2 Maruyama Masao focused on "intentionality" in his understanding of early modern Confucianism centered on Sorai studies (Maruyama 1940). Naturally, his interest in "shuyo" was minimal.

3 Foucault also sees the individual and society as continuous: the shuyo (subjectification) of the individual is obedience (submission) to authority. In contrast, the Neo-Confucian individual is "the one with the potential to govern," and Neo-Confucian shuyo is "the process of cultivating the virtues of the ruler."

4 According to Sorai, a focus on internal shuyo is no more than a misreading of the scriptures under the influence of Buddhism and Taoism.

5 Baigan has been discussed elsewhere (Nishihira 2014, Chapter 8).

6 Theories of shuyo in the Meiji period typify "discipline." Their shuyo was called on to act as a new moral awareness for the people of the nation (Tsutsui 1995).

7 Issues include: can care for the self become the basis of resistance? Does it enable "parrhesia" open to others? Can we find these possibilities in Edo-period shuyo ideology as well? (Nishihira 2014, Ch. 8)

8 Yuasa introduces the "religious commandments" of Chinese Buddhism, noting that they are commandments imposed on the self rather than enforced externally. This overlaps with the understanding of shuyo in Neo-Confucianism (Cheng-Zhu and Song Neo-Confucianism).

9 The self, having lost its "innocent spirit," returns to "innocence" via "shikan (calming) shuyo," of the same type as "mushin" in the ideology of keiko (Nishihira 2014). "shi" refers to the stilled work of the spirit and "kan" to the calm observation of the self and the world.

10 Thorough practice of the vertical axis leads to Dogen Zenji's "shusho itto" or "oneness/equality of practice and realization" (Nishihira 2019, Ch. 12).

11 "Shenxian" practitioners whose ideal was long life and immortality, aiming to become immortal sages through the five laws of meditation, breathing, diet, coition, and good deeds.

12 According to the Daikanwa Jiten Chinese dictionary (Morohashi Tetsuji), shuyo is "originally a Daoist method of yojo, thus becoming used to indicate bettering the path and cultivating virtue."

13 The study examines sekimon-shingaku (its final form in the late Edo Bakumatsu period) and the popularly available Zen movement at Enkakuji in Kamakura, as well as introducing the "unique practical self-improvement techniques" of Misogi, a quasi-Shinto sect.

\section{Works Cited}

Ashida Enosuke (1988) "Tsuzurikata kyoju ni kansuru kyoshi no shuyo (Teachers' shuyo in composition education)" in Ashida Enosuke Kokugo Kyoiku Zenshu (Complete Works of Ashida Enosuke on Japanese Language Education), Meiji Tosho (first edition 1915)

Carter, Robert E. (2008) The Japanese Arts and Self-Cultivation, State University of New York Press

Dore, Ronald P. (1965) Education in Tokugawa Japan, University of California Press (Japanese trans. Matsui Hiromichi, Iwanami Shoten, 1970)

Dumont, Louis (1994) German Ideology: From France to Germany and Back, The University of Chicago Press 
Foucault, Michel (2004) The Hermeneutics of the Subject: Lectures at the Collège de France 19811982 (Japanese trans. Hirose Koji/Hara Kazuyuki), Chikuma Shobo

Hadot, Pierre (2002a) What is Ancient Philosophy? trans. Michael Chase, Cambridge, Massachusetts / London, Belknap Press of Harvard University Press,

Hadot, Pierre (2002b) Exercices spirituels et philosophie antique, nouvelle éd. Paris, Albin Michel

Imamura Hitoshi (2004) Kiyozawa Manshi to tetsugaku (Kiyozawa Manshi and Philosophy), Iwanami Shoten

-- ed. (2001) Gendaigoyaku Kiyozawa Manshi Goroku (Modern Japanese Translation of Kiyozawa Manshi's Writings), Iwanami Gendai Bunko

Imamura Yoshio (1967) Jukyuseiki ni okeru Nihon no taiiku no kenkyu (Research on $19^{\text {th }}$-Century Japanese Physical Education), Fumaido Shoten

Inoue Tetsujiro (1900) Nihon yomeigakuha no tetsugaku (Philosophy of the Japanese Yangmingist School), Fuzambo

Kaibara Ekken (1982) Yojokun, Kodansha Gakujutsu Bunko (first edition 1713)

Karaki Junzo (1963) Gendaishi e no kokoromi (Approaches to Modern History), Chikuma Shobo

Koyasu Nobukuni (1990) 'Jiken' to shite no Soraigaku (Sorai Studies as 'Incidents'), Seidosha

-- (1998) Edo shisoshi kogi (Lectures on Edo Ideological History), Iwanami Shoten

Maruyama Masao (1940) "Kindai Jukyo no hatten ni okeru Soraigaku no tokushitsu narabi ni sono kokugaku to no kankei (The characteristics of Sorai studies in the development of modern Confucianism and the relation with his kokugaku national study)" (in Nihon seiji shisoshi kenkyu (Research on the History of Japanese Political Ideology), University of Tokyo Press, 1952)

Masu Nobuo (2016) "Seika no yotai kara miru Bildung, shuyo, kyoyo (Bildung, shuyo, and kyoyo viewed from the manner of sanctification)" (Toin Hogaku 23-1)

Miyakawa Toru (1980) Nihon seishinshi no kadai (Issues in Japanese Spiritual History), Kinokuniya Shoten

Nishihira Tadashi (1999) "Chi no wakugumi to shite no [seishin sekai]: Kyokanteki rikai to hihanteki kento (The [spiritual world] as a framework for knowledge: Empathic understanding and critical examination") (Kyoikugaku kenkyu 66-4)

-- (2009) Zeami no keiko tetsugaku (Zeami's Philosophy of Keiko) University of Tokyo Press

-- (2014) Mushin no dynamism (The Dynamism of Mushin), Iwanami Gendai Zensho

-- (2019) Keiko no shiso (The Philosophy of Keiko), Shunjusha

Nitobe Inazo (1911) Shuyo (in Nitobe Inazo Zenshu (Collected Works of Nitobe Inazo) Vol. 7, Kyobunkan, 1970

-- (1899) Bushido: The Soul of Japan (in Nitobe Inazo Zenshu (Collected Works of Nitobe Inazo) Vol. 12 (Japanese text 1900, Vol. 1) Kyobunkan, 1970

Saigusa Hiroto ed. (1956) Nihon tetsugaku shiso zensho (Collected Japanese Philosophical Thought) "Shuyo hen/sado hen (Volumes on shuyo and tea ceremony)" Heibonsha

Saito Naoko, Paul Standish, Imai Yasuo ed. (2018) 'Honyaku' no sanaka ni aru shakai seigi (Social Justice in Translation), University of Tokyo Press

Sawada, Janine T. (2004) Practical Pursuits: Religion, Politics, and Personal Cultivation in Nineteenth-Century Japan, University of Hawai 'i Press

Takizawa Toshiyuki (2003) Yojoron no shiso (Ideology of Yojo Theory) Seori Shobo

Tsujimoto Masashi (2011) Shiso to kyoiku no media shi: Kinsei Nihon no chi no dentatsu (Media History of Ideology and Education: Transmission of Knowledge in Early Modern Japan) Pelicansha

Tsutsui Kiyotada (1995) Nihon-gata 'kyoyo' no unmei: Rekishi shakaigakuteki kosatsu (The Destiny of Japan-style 'Kyoyo': A Sociohistorical Consideration) Iwanami Shoten

Tucker, Mary Evelyn (1989) Moral and Spiritual Cultivation in Japanese Neo-Confucianism: The Life and Thought of Kaibara Ekken, State University of New York Press

Uchimura Kanzo (1908) Daihyoteki Nihonjin (Representative Men of Japan) (Iwanami Bunko 1995, first English edition 1908)

Wang Cheng (2004) "Kindai Nihon ni okeru [shuyo] gainen no seiritsu (The establishment of the 
concept of shuyo in prewar Japan)" Nihon Kenkyu 29

Watanabe Hiroshi (2010a) Nihon seiji shisoshi (A History of Japanese Political Thought, 1600-1901) University of Tokyo Press (English trans. David Noble, International House of Japan, 2012)

-- (2010b) Kinsei Nihon shakai to Sogaku (Early Modern Japanese Society and Song Confucianism) University of Tokyo Press, first edition 1985

Yamamoto Masami (2010) Jinsaigaku no kyoiku shisoteki kenkyu: Kinsei kyoiku shisho no shii kozo to sono shisoshiteki tenkai (Educational Ideology-based Research on Jinsai Studies: Thought Structure of Early Modern Educational Ideology and its Development in the History of Ideology) Keio University Press

Yuasa Yasuo (1977) Shintairon: Toyoteki shinshinron to gendai (The Body: Toward an Eastern MindBody Theory) (Kodansha Gakujutsu Bunko 1990, first edition 1977; English trans. Shigenori Nagatomo and Thomas P. Kasulis, SUNY Press, 1987)

The following books and papers further develop the ideas presented herein:

Nishihira, Tadashi (2020) Self-Cultivation in Japanese Traditions, Journal of Educational Philosophy and Theory, Philosophy of Education in a New Key: East Asia (A collective project of the PESA executive), Published online: 28 May 2020

--(2020) Shuyo no shiso (The Philosophy of Shuyo), Shunjusha

--(2021) Yojo no shiso (The Philosophy of Yojo), Shunjusha

--(2021) (with Rappleye, Jeremy), Unlearning as (Japanese) Learning, Educational Philosophy and Theory (EPAT), Japanese Special Issue, forthcoming 